\title{
ENSAIO SOBRE UMA GEO-GRAFIA DOS GRAFFITIS'
}

\author{
DENÍLSON ARAÚJO DE OLIVEIRA \\ Universidade Estadual do Rio de Janeiro \\ LEANDRO TARTAGLIA \\ Universidade Estadual do Rio de Janeiro
}

Nossa proposta de análise neste artigo se desdobra em três partes. $\mathrm{Na}$ primeira, apresentamos o contexto de emergência dos graffitis urbanos contemporâneos. Entendemos que eles se estruturaram como uma prática do hip-hop nos anos 60/70 e se difundiram para o mundo, adaptando-se a cada realidade em seu processo de des-re-territorialização. Analisamos o contexto tenso de sua emergência e as mudanças de significado social que os graffitis de hip-hop passaram. Na segunda parte do artigo problematizamos a ação dos grafiteiros como um dos elementos centrais na construção de suas identidades, diferenciando-a de outros inúmeros grafismos urbanos. Na terceira e última seção buscamos investigar os significados que os graffitis vêm imprimindo à cidade, em especial a do Rio de Janeiro. Colocamos em discussão nessa parte derradeira os grafismos urbanos, especialmente os grafittis de hip-hop, a partir dos conceitos de territorialidade e paisagem na dinâmica do urbano contemporâneo. Usamos esta distinção em três partes a fim de investigar os dilemas e desafios criados por essas inscrições na paisagem que comunica uma estratégia territorial, que torna a arte pública uma experiência de todos e humaniza as paisagens projetadas de acordo com a lógica do capital, com uma estética vibrante de cores e técnicas.

\footnotetext{
1

. Torna-se relevante destacar nossa participação direta, seja através de nossas pesquisas, ou pela execução de oficinas, intervenções na cidade (graffitis) ou em mutirões, decorrente de nossas próprias identificações e vinculações com o movimento que foram base para a construção deste artigo.
} 


\section{A emergência dos graffitis de hip-hop}

A palavra grafite vem do italiano "graffiti", que é plural de graffito. Graffito significa, em latim e italiano, "escritas feitas com carvão". Os antigos romanos tinham o costume de escrever com carvão nas paredes de suas construções manifestações de protesto, palavras proféticas, ordens comuns e outras formas de divulgação de leis e acontecimentos públicos, como se fossem mensagens em cartazes. ${ }^{2}$

A arte pública dos graffitis, ao abdicar do cenário ainda pouco acessível de museus e galerias pelas populações das periferias, ao optar pela rua como espaço de enraizamento enquanto seu território, expressa a compreensão do estético não mais como privilégio de iniciados, mas sim como valor a ser partilhado por todos. (OLIVEIRA, 2004: 54)

Os graffitis, tais como conhecemos atualmente, expressos nas paisagens de diversas cidades ao redor do mundo, com suas cores e formas vibrantes e impactantes, são um dos elementos constituintes da cultura hiphop.

A cultura hip-hop tem como seu epicentro a cidade de Nova York nos anos 60/70, especialmente no Bronx, como uma prática reconstruída pelos imigrantes jamaicanos que criavam uma nova forma de convivência social nos guetos através das suas antigas festas de rua, as chamadas sound-systems. Essas festas criavam espaços de celebração da multiplicidade que atraía jovens para a diversão e o encontro com os imigrantes porto-riquenhos, mexicanos, haitianos e afro-americanos, entre outros, que assim transferiam os conflitos violentos entre as gangues, ou seja, uma geopolítica urbana (GOMES, 2002) de disputas territoriais para as disputas musicais (os desafios de rap), disputas de dança (as batalhas de street dance e break) e as disputas estéticas visuais (competições de quem fazia os melhores desenhos e os mais difundidos pela cidade, os graffitis). Neste sentido, criavam práticas espaciais conciliatórias através de elementos culturais. Todavia, isso não significa que os graffitis de hip-hop dissimulavam totalmente os conflitos; pelo contrário, num primeiro momento os graffitis foram estratégias territoriais que demarcavam a

2 Retirado do endereço eletrônico da Cufa (Central Única de Favelas) WWW.cufa.com.br, acessado em 14/09/03. 
disputa por territórios entre gangues, especialmente de imigrantes, para depois se tornar uma estética de conciliação para esses grupos.

Segundo as informações retiradas no endereço eletrônico da $\mathrm{Cufa}^{3}$ :

Há duas teorias que explicam a origem dos grafiteiros modernos. Para ser sincero, uma completa a outra: há quem diga que o graffiti surgiu com o hip-hop, uma cultura de periferia, originária dos guetos americanos que une o rap (música muito mais falada do que cantada), o break (dança robotizada) e o graffiti (arte plástica do movimento cultural). Nos EUA, principalmente nos bairros pobres de Nova York, era comum que os moradores de periferia, impossibilitados de participar dos eventos da cidade, que exigiam um certo poder aquisitivo, fizessem festas de rua, conhecidas como "bailes black". No geral, os promotores dessas festas faziam parte de gangues que representavam e defendiam seus bairros. Mais do que defesa, havia muita rivalidade entre uma gangue e outra. Para que seus integrantes pudessem se comunicar, eles escreviam com letras ilegíveis [letras estilizadas] e faziam desenhos quase incompreensíveis nos muros dos guetos, numa espécie de código secreto. Costuma-se dizer que o código evoluiu para arte e ganhou o mundo.

A primeira teoria sobre os graffitis urbanos contemporâneos afirma um elemento que já apontamos, os graffitis de hip-hop envolvidos e constituindo arenas territoriais. Porém, a segunda interpretação para a emergência desse elemento do hip-hop é um pouco diferente.

[...] A outra teoria afirma que o graffiti teria surgido também em Nova York e de lá se espalhado pelo mundo.

Desde o início os artistas, também chamados de writers (escritores), costumavam escrever seus próprios nomes ou chamar a atenção para problemas do governo ou questões sociais da realidade em que viviam. Tais desenhos eram feitos, em sua maioria, em trens, porque o verdadeiro interesse do grafiteiro era passar aquela mensagem para o maior número possível de pessoas. Sem os trens, isso talvez não fosse realizado. Outra possibilidade aproveitada pelos

3

Ver nota anterior. 
grafiteiros para passar as suas mensagens era espalhar suas grandes ideias pelos muros da cidade.

Esta segunda proposta de gênese dos graffitis expressa uma apropriação da rede ferroviária de Nova York feita pelos primeiros grafiteiros como forma de comunicação com os transeuntes do metrô e entre grafiteiros distantes uns dos outros. Cabe destacar que nem todos os grafiteiros que adotavam esta estratégia estavam necessariamente vinculados ao hip-hop (KNAUSS, 2001).

$\mathrm{O}$ que ambas as teorias expressam é que o graffiti de hip-hop surge como uma das estratégias territoriais de uma cultura política, que expressa uma forma de (r)existência (PORTO-GONÇALVES, 2002; OLIVEIRA, 2004) dos negros e imigrantes "latino-americanos", os quais sempre foram altamente discriminados perante a elite de sociedades como a dos EUA, e que, através da arte visual, rompem com o anonimato nas cidades. Por ocupar inicialmente as ruas dos guetos de Nova York pela música, a dança e a arte plástica (o graffiti), a cultura hip-hop potencializou outras formas de existir dessas populações para além dos bairros em que habitavam, imprimindo, inclusive, marcas como os graffitis nas paisagens dessa e de outras cidades. Esta associação entre os elementos do hip-hop e o espaço urbano tornou-se vital, ampliando sua repercussão e mundializando-se nos anos subsequentes (RODRIGUES, 2003; OLIVEIRA, 2004).

Os graffitis urbanos contemporâneos sugiram no bojo da luta em defesa dos direitos civis nos EUA, sendo adotados pelo movimento Black Power em 1967, na cidade de Chicago, com a inauguração de uma pintura mural coletiva, resultado da intervenção de 21 artistas negros que dividiram uma fachada, intitulada Wall of Respect $^{4}$ (KNAUS, 2001). Outras pinturas murais foram construídas nas ruas de distintas cidades americanas, com a participação de outros grupos subalternizados, como os chamados chicanos. Estes traziam consigo a forte influência decorrente, principalmente, da pintura muralista mexicana, que teve ingerência ativa na revolução política ocorrida nesse país no início do século XX (KNAUS, 2001). Podemos apontar também certa aproximação entre os graffitis de hip-hop e as inscrições de cunho político durante as revoltas estudantis em maio de 1968 na França, como um marco de manifestações e uso político

4 As referências que tivemos sobre a emergência dos graffitis urbanos contemporâneos foram a cidade de Nova York (EUA). Usamos o exemplo da cidade de Chicago (EUA) para apontar a relação que o graffiti passava a ter com um movimento que tinha, nos anos 60, a cultura negra como um dos seus elementos centrais. 
do espaço a partir da elaboração de grafias e pinturas que ilustraram a paisagem urbana ${ }^{5}$ e social daquele momento. A pop art apresentou desde os anos 60 a reprodutibilidade como mecanismo de difusão em massa da produção artística para a individualização de imagens. Os graffitis passaram a ser feitos mediante a utilização deste mesmo recurso.

Knauss (2001) afirma que a história do desenvolvimento dos
graffitis urbanos contemporâneos está relacionada ao contexto
dos anos 60/70, momento em que aparecem diferentes
tradições de inscrever com imagens e palavras, muitas vezes
irreverentes, em relação à ordem social nas cidades francesas,
inglesas e americanas, entre outras. A expressividade desses
graffitis, antes mesmo de sua articulação com o hip-hop, já
emergia na geração dos anos 60, ligada ao momento político
(no maio de 68 na França, nos movimentos contra as
ditaduras militares na América Latina, nos protestos urbanos
na Inglaterra, na luta pelos direitos civis nos EUA e outros).
Ao se inscreverem nas paisagens urbanas nesse período, os
graffitis passaram a produzir outra comunicação estética da
cidade ${ }^{6}$. Essa forma de produção artística, para alguns
autores, como Baudrillard (1979), não é nova. A escrita em
paredes vem desde os tempos das cavernas e foi utilizada por
distintas culturas como expressão dos desejos e de protestos.
A cultura Hip-Hop irá fazer dos graffitis um dos seus
elementos. (OLIVEIRA, 2006:108/109)

Todavia, a ação dos grafiteiros será convertida em questão policial, principalmente pela imprensa nova-iorquina, no início dos anos 70 (KNAUSS, 2001) com o debate em torno da underclass (WACQUANT, 2001). O graffiti, neste caso, foi visto como uma ação de vandalismo decorrente da rivalidade entre grupos de jovens ou gangues pertencentes aos guetos de imigrantes e negros, manifestando-se através da demarcação

5 Jonhn Downing (2002) lembra que os graffitis não se restringiram ao mundo capitalista. Jovens na Moscou dos anos 70 e 80 grafavam nas paredes dos grandes e sombrios edifícios de apartamentos declarações sobre rock escritas em inglês, provocando o regime soviético da época, que definia o rock e o jazz como uma decadente e insalubre influência estrangeira sobre a juventude soviética.

Entendemos como inscrever, ou inscrição, o registro pelo entalhe e a composição de uma obra dos sujeitos e de todo seu imaginário social e coletivo. 
e depredação de estátuas, muros altos e marquises em diferentes partes da cidade.

Nos anos 70, o graffiti era utilizado principalmente como uma assinatura que demarcava os territórios disputados por grupos de jovens, negros e "latino-americanos" em sua maioria, pelos bairros da cidade de Nova York. Até então não havia uma unidade entre esses grupos que, apesar de sofrerem preconceitos e discriminações perante a elite branca da sociedade estadunidense, estabeleciam entre si uma grande rivalidade. A paisagem então era demarcada com as assinaturas que identificavam as gangues juvenis, também conhecidas como Tag. O espaço, assim, era dividido e territorializado.

As crews possuem territórios demarcados dentro dos bairros
nova-iorquinos. Essa marcação territorial se dá, no seu
aspecto mais visível, pelos graffitis que são pintados nas áreas
dominadas. Cada crew tem o seu Tag (assinatura) e o espalha
pelos muros e vagões de metrô (COSTA, 2002: 07$)^{7}$.

A perseguição policial, tal qual a campanha anti-grafitti promovida pelo governo da cidade de Nova York, era bastante enfática nesse momento. Altos investimentos foram feitos por organismos públicos para o combate aos grafiteiros, inclusive com um grande número de prisões. Esse fenômeno da repressão não se restringiu aos EUA (KNAUSS, 2001). No Brasil, os primeiros graffitis, nos anos 80, receberam inicialmente o rótulo genérico de pichação, homogeneizando um campo diverso de manifestações e tornando-se, em cidades como Rio de Janeiro e São Paulo, uma questão de limpeza pública. Entretanto, isso não conteve a produção estética tanto nos EUA quanto no Brasil, que acabou se distanciando da lógica de rasuras a monumentos históricos e prédios públicos, passando a produzir uma estética urbana ligada à arte.

O princípio de institucionalização como forma de arte se deu nos EUA durante os anos de 1972 e 1973, com a participação de intelectuais e um diálogo com uma produção artística institucionalizada, foi acompanhada pela diminuição da sua produção e a sua universalização.

7

Knauss (2001) afirma que os Tags são assinaturas ou contra-senhas utilizadas para demarcar os territórios dos grafiteiros. Costa (2002) afirma que também as gangues de break tinham seus Tags. 
No percurso da institucionalização do graffiti como criação artística dois personagens teriam aí um papel importante, percorrendo caminhos inversos. Keith Harring (1958-1990), nascido em Pittsburgh, chegou a Nova York no fim da década de 1970, onde cursou por dois anos a School of Visual Arts. Inspirado na obra do francês Jean Duduffet e nas reflexões de Umberto Eco, Harring iniciou seu percurso de grafiteiro nas paredes do metrô de Nova York e levou a linguagem do graffiti e dos quadrinhos para as telas, realizando trabalhos de caráter performático, muito próximo de uma cultura da espontaneidade que marcou a relação das artes com a improvisação na América pós-guerra. [...] O caso de JeanMichel Basquiat (1960-1986) representa exatamente o percurso inverso, de alguém que saiu das ruas e ganhou a consagração das galerias e museus de arte contemporânea. Filho de uma porto-riquenha e um haitiano, nascido no Brooklyn, em Nova York, Basquiat deixou de ser SAMO grafiteiro ao transformar sua obra pelo diálogo com a produção artística contemporânea, especialmente a partir de sua relação com Andy Warhol (KNAUSS, 2001:329).

Em "Kool Killer", texto de J. Baudrillard (1976) sobre o tema em questão, não fica evidente uma diferenciação muito precisa para o que chamamos de graffiti, que por alguns momentos se confunde com algo mais próximo ao que se pode entender como a pichação. $\mathrm{O}$ autor aponta um fenômeno que ainda estava em seus primórdios, que de fato ainda assumia uma série de características semelhantes ao que viemos a chamar de pichação ${ }^{8}$.

A pichação pode ser também chamada de Tag. Essa assinatura é normalmente um pseudônimo adotado pelo autor, muitas vezes por questões de ordem subjetiva, e que tem como lógica a difusão máxima pela paisagem da cidade. As assinaturas, feitas em letras tramadas e tecnicamente repetitivas, são realizadas em profusão por muros, monumentos e outros artefatos urbanos. Sua lógica é não respeitar a propriedade privada ou os artefatos tombados pelo patrimônio público. Por

8

Pichação foi um termo cunhado no Brasil para identificar um tipo de grafismo urbano, originado a partir da utilização do uso da substância viscosa e de difícil remoção denominada piche por estudantes para escrever frases políticas contra o regime militar nos anos 70. Hoje a pichação é observada na paisagem "escalando" as fachadas e edificações, o que representa a aventura e subversão de seus autores. 
isso, a pichação é radicalmente combatida pelos órgãos institucionais de controle urbano e discriminada socialmente pelo seu caráter de vandalismo. Para os pichadores, quanto mais difícil for o acesso ao local pichado, maior o mérito da ação. Dessa forma as pichações passaram a seguir um sentido vertical na paisagem, isto é, seus autores passaram a escalar literalmente prédios e outras edificações urbanas, em busca de visibilidade dentro de uma perspectiva da dificuldade de acesso e aventura'. Se o local tiver uma grande vigilância, potencializa seu valor simbólico de conquista para o pichador.

Conforme o próprio Baudrillard afirma:

Os graffítis provêm da categoria do território. Eles territorializam o espaço urbano decodificado - esta rua, aquele muro, tal quarteirão assumem vida através deles, tornando-se coletivos. E eles não se circunscrevem ao gueto; exportam o gueto para todas as artérias da cidade, invadem a cidade branca e revelam que ela é o verdadeiro gueto do mundo ocidental (BAUDRILLARD, 1976:38, grifos nossos).

Afirmamos que o graffiti assume características claramente distintas da pichação. Primeiramente, o graffiti tem uma preocupação estética muito maior que a pichação (ver quadro 1). A proposta de demarcação territorial que era feita através dos graffitis foi sendo diluída ao longo das décadas, passando a representar uma arte marginal repleta de valores políticos, estéticos e técnicos. O graffiti deixou de representar o símbolo de apenas um grupo específico, passando a ser um símbolo de uma cultura urbana subalternizada que é mundializada devido às semelhanças encontradas nas mais diversas cidades do mundo, veiculado pela possibilidade de difusão de informações pelos meios de comunicação.

O graffiti, parte constituinte da cultura hip hop, irá se mundializar nos anos 1970/80, especialmente através de filmes que retratam as cidades americanas, principalmente os guetos em sua visão estereotipada da underclass, ou por meio da valorização artística e mercadológica desta prática urbana que passa a ter grande aceitação em galerias de arte e centros culturais a partir desse período, passando a se territorializar de diferentes formas em várias partes do mundo e (r)existindo a cada formação sócio-espacial.

9

O que por vezes ocasionou inclusive a morte de pichadores. 


\section{É importante aqui lembrar Rodrigues, quando coloca:}

A globalização do Hip-Hop foi um processo que ocorreu de forma rizomática e molecular (Deleuze e Guattari (1994) e Guattari e Negri [1982]). De forma rizomática porque os elementos do hip-hop foram se globalizando de forma descentralizada, ou seja, eles não partiam de um determinado centro para chegar a um outro lugar, não havia um centro de comando; a globalização ocorreu de forma não hierárquica, ou seja, nenhum dos elementos tinha uma posição superior aos demais, não havia uma ordem de importância dada a priori. O rizoma deve ser entendido como um processo onde as multiplicidades (no caso o rap, o break, o graffiti, o dj, a luta contra o racismo, contra a violência policial etc.) se conectam umas às outras sem responder a um centro de comando ou a ordens hierárquicas. De forma molecular porque a sua constituição enquanto movimento social se faz de forma imanente às singularidades dos grupos e dos indivíduos, não há uma figura transcendente que organiza o socius de forma centralizada (como o Estado, os partidos ou o capital). (RODRIGUES, 2003:32/33)

\section{A construção social do grafiteiro}

Entender o graffiti pressupõe uma compreensão de quem o faz. Como e onde são feitos também são questionamentos relevantes. Por isso, voltamos nosso olhar para o sujeito dessa ação, o grafiteiro. Ser grafiteiro hoje no Brasil, especialmente no Rio de Janeiro, deriva de todo o processo descrito anteriormente, mas que vem mudando consideravelmente sua forma de inserção na sociedade. Privilegiamos aqui o Rio de Janeiro em nossa análise, por se tratar da cidade em que vivemos e focamos nossos estudos.

Buscamos compreender até que ponto a constituição dessa identidade artística e urbana é de fato capaz de criar sujeitos e ações responsáveis pela subversão da ordem instituída. Esta discussão torna-se relevante e ambígua no momento presente em que assistimos à utilização e divulgação de uma imagem positiva do graffiti e de seus autores nos veículos de comunicação de massa (televisão, jornais, revistas, propagandas). 
No âmbito jurídico o graffiti é considerado uma atividade criminosa, segundo a lei de crimes ambientais:

\section{Seção IV}

Dos Crimes contra o Ordenamento Urbano e o Patrimônio Cultural

Art. 65. Pichar, grafitar ou por outro meio conspurcar edificação ou monumento urbano:

Pena - detenção, de três meses a um ano, e multa.

Parágrafo único. Se o ato for realizado em monumento ou coisa tombada em virtude do seu valor artístico, arqueológico ou histórico, a pena é de seis meses a um ano de detenção, e multa. (Lei de Crimes ambientais 9.605/ 1998)

Afirmamos anteriormente que o graffiti apresenta diferenças da pichação que vão além da sua concepção estética. Essa distinção passa pelo tratamento diferenciado que seus respectivos autores acabam recebendo a partir de suas práticas, mesmo que a lei estipule um tratamento semelhante para grafiteiros e pichadores. O grafiteiro, diferentemente do pichador, principalmente ao longo da última década, conseguiu ampliar a aceitação de sua prática pela cidade, desvinculando-se da imagem de vandalismo à qual muitas vezes esteve associado ${ }^{10}$. Por outro lado, o pichador continua sendo reconhecido nos diferentes setores da sociedade como vândalo. $\mathrm{O}$ mais interessante é notar que os próprios pichadores procuram manter esta reputação e reconhecem suas ações como uma afronta aos valores estéticos e paisagísticos hegemônicos nas cidades (GITAHY, 1999; ARCE, 1999; SOUZA, 2007).

Estudos recentes, como os de De Diego (2000), Pennachin (2003), Munhoz (2003), Souza (2007) e Tartaglia (2007), apontam que o grafiteiro e o pichador têm uma origem em comum e que muitas vezes uma imagem, seja ela graffiti ou picho, pode ser feita por uma mesma pessoa ou grupo (também denominado de crew). Inclusive a cultura da pichação está presente na realidade brasileira, em especial no Rio de Janeiro, há mais tempo que o graffiti ou mesmo que o hip-hop. Por isso, muitos foram

10 Mesmo assim o graffiti também pode ser utilizado como forma de agredir esteticamente a paisagem, como demonstra o nome da crew de grafiteiros intitulada "Destruidores do Visual (DV)". 
pichadores antes mesmo de se tornarem grafiteiros. É importante ressaltar que muitos pichadores e grafiteiros não consideram que uma prática é evolução da outra, como a mídia em geral retrata o graffiti em relação à pichação. No entanto, tornar-se grafiteiro exige uma grande destreza com a tinta spray, ou o desenvolvimento dela, mesmo que o pichador já a tenha, pois necessita também de um senso estético, técnico e criativo mais refinado $^{11}$.

A partir das nossas observações e participações em campo, especialmente em oficinas de graffiti realizadas semanalmente no centro do Rio de Janeiro e em eventos específicos de graffiti também chamados de mutirões, constatamos uma variabilidade significativa de perfis sociais frequentando esses encontros de grafiteiros. Não foi possível estabelecer um perfil mais característico que denotasse inclusive um comprometimento ideológico ou político por grande parte de seus frequentadores. De fato há um predomínio de homens grafiteiros com idade entre 15 e 30 anos, desde os mais experientes, alguns já na faixa dos 40 anos, aos novatos. Mesmo assim, destaca-se um grupo ainda pequeno, mas atuante, de mulheres em uma faixa etária correspondente. Negros e pardos igualam-se em número aos brancos. A partir de entrevistas e conversas informais contatou-se uma multiplicidade de grafiteiros oriundos de diversas partes da cidade do Rio de Janeiro e municípios vizinhos, o que implica pensar que há uma variação de indivíduos pertencentes a classes sociais e padrões de renda distintos.

Dessa forma é quase impossível atribuir um perfil social exclusivo aos grafiteiros no Rio de Janeiro. Mesmo que a diferença seja predominante entre os grafiteiros e por isso agregue aparentemente um grupo heterogêneo, o que estabelece unidade e confere-lhes identidade é a prática do graffiti, independentemente do estilo, do tempo de atuação ou da motivação.

11 Em todo o trabalho usamos a palavra técnica(o) no sentido grego de techn, de arte e habilidade na produção de algo inesperado. Marilena Chauí lembra que "a palavra arte vem do latim ars e corresponde ao termo grego techne, técnica, significando: o que é ordenado ou toda espécie de atividade humana submetida a regra. Em sentido lato, significa habilidade, destreza, agilidade. Em sentido estrito, instrumento, ofício, ciência" (CHAUÍ, 2001). As técnicas de grafitti são a expressão de várias experiências estéticas. Nossa atenção à técnica busca romper a negligência das técnicas apontadas por Santos (2002 [1996]) e também uma infeliz letargia de aproximação dos geógrafos do campo da arte. 
Portanto, entender o grafiteiro na cidade do Rio de Janeiro atualmente é uma tarefa no mínimo complexa e sujeita a uma grande variabilidade de perfis sociais que partilham desta identidade ${ }^{12}$. Essa multiplicidade de grafiteiros não apresenta uma coesão ideológica ou mesmo um projeto político e objetivos comuns. Pode-se dizer inclusive que a atuação dos grafiteiros não está exclusivamente ligada ao movimento hip-hop, o que denota uma grande diferença na atuação dos grafiteiros em grupos menores (entre três e dez membros) ou individualmente.

A partir da identificação de dois grupos distintos de grafiteiros é possível notar como ocorre a inter-relação entre os aspectos que marcam sua forma de atuação no espaço metropolitano do Rio de Janeiro. Selecionamos a Fleshbeck crew e a Posse 471 para a análise.

O primeiro grupo é composto por cinco membros com idades entre 25 e 35 anos, com formação superior em desenho industrial e que hoje atuam prioritariamente na confecção artística de produtos como estampas de roupas e rótulos, propagandas de eventos, decoração de residências, galerias e cenografia. Entre seus principais clientes estão Rede Globo, Coca Cola, Oi, Credicard, Nestlé, entre muitos outros ${ }^{13}$. A Fleshbeck é uma das crews pioneiras do graffiti carioca surgida no final da década de 90. Nas ruas, tem sua atuação concentrada na forma de "bombardeios" na Zona Sul e no Centro da cidade.

A Posse 471 tem sua origem na Baixada Fluminense em um período relativamente próximo. Seus membros, que variam entre artistas autodidatas e de formação superior, têm atuações distintas em municípios metropolitanos do Rio de Janeiro. No entanto, destacam-se pela mobilização e articulação em torno do evento anual "Meeting of favela", Este evento de caráter festivo reúne grafiteiros de várias partes do Brasil e de outros países para pintar as fachadas e construções de uma favela localizada no município de Duque de Caxias, denominada Vila Operária.

Os dois grupos apresentam distinções ideológicas em suas ações, o que implica diferentes formas de apropriação do espaço urbano. É preciso

12

Tarefa que se torna ainda mais difícil pelo fato de os grafiteiros assinarem em suas pinturas um apelido, o que não permite a sua real identificação. A isto Knauss (2001) denomina de contra-senhas, uma espécie de pseudônimo que garante o anonimato como indivíduo e a notoriedade como grafiteiro.

13 Ver <http://www.fleshbeck.com.br/index.asp> (acessado em 11/05/2010).

14 Ver $<$ http://meetingofavela.blogspot.com $>$ acessado em 16/05/2010. 
pensar inicialmente que não há uma coesão de projetos entre os grafiteiros configurando uma forma de movimento social urbano clássico (GOHN, 1997). Motivados por interesses profissionais e mercadológicos, o primeiro grupo inseriu de forma eficaz seus graffitis em pontos de alta visibilidade para parcelas de poder aquisitivo mais elevado na cidade do Rio de Janeiro. Categorizados como artistas de rua, viram suas obras ganhar valor no mercado de arte e decoração. Das ruas passaram para os trabalhos particulares e desenvolveram outras formas de inserção no mercado profissional de arte e designer como grafiteiros, motivados pela procura e valorização de suas obras. O segundo grupo busca também uma inserção profissional no mercado de arte, mesmo não atingindo um nível tão elevado de renda e divulgação midiática. Seja pela atuação em uma parte do espaço urbano cujo poder aquisitivo é mais baixo, seja pela própria seletividade do mercado que impede a sua plena democratização.

A Posse 471 apresenta outro perfil de grafiteiros atuantes no Rio de Janeiro, o que envolve em parte uma condição de renda e moradia específica, mas principalmente outras formas de apropriação do espaço urbano. Uma de suas formas de apropriação mais significativa ocorre em uma área periférica à metrópole carioca, ocupando um espaço popular através da intervenção artística e promovendo a interação entre grafiteiros e os moradores dessa comunidade ${ }^{15}$. Promovendo uma espécie de retorno aos tradicionais sound-systems a partir das intervenções características do hip-hop (graffiti, música, festa, improviso) no espaço público das comunidades como forma de práticas conciliatórias. Os mutirões, como ficaram conhecidos, têm ocorrido com frequência em diversas outras partes consideradas periféricas e abandonadas do Rio de Janeiro, articulados inclusive por outras crews, com apoio de outros movimentos sociais, ONGs e até empresas patrocinadoras.

Por fim, destacamos que não há uma rivalidade explícita entre esses grupos, mesmo que representem interesses antagônicos a partir de suas práticas. O que ocorre é a distinção das formas de apropriação do espaço urbano, fazendo uso inclusive de suas diferentes potencialidades. A intencionalidade dos grafiteiros define a forma e o local das suas intervenções. Esta diferença aparece na inter-relação entre os aspectos: grupo de grafiteiros - objetivos - área de atuação. Ao contrário do pichador, o grafiteiro pode assumir essa identidade para assim conseguir

15

Essa apropriação ocorre anualmente na forma de um mutirão chamado "Meeting of favela", na comunidade da Vila Operária, em Duque de Caxias, RJ. 
uma acessibilidade diferenciada na cidade, seja como forma de manifestação cultural e política, ou mesmo para a geração de trabalho e renda através do graffiti.

\section{Apropriação do espaço urbano e territorialidade dos grafiteiros}

O graffiti, que está inserido na definição de grafismos urbanos, se faz por meio da intervenção direta. Esse processo pode ser também analisado dentro da perspectiva do que Lefebvre chama de apropriação do espaço. Como uma espécie de direito à cidade, a apropriação do espaço urbano para Lefebvre pode ser entendida da seguinte forma:

O direito à cidade se manifesta como forma superior de direitos: direito à liberdade, à individualização na sociedade, ao habitat e ao habitar. O direito à obra (à atividade participante) e o direito à apropriação (bem distinto do direito á propriedade) estão implicados no direito à cidade. (LEFEBVRE, 2006:135)

O conceito de apropriação simbólica de Lefebvre (2006) será aqui utilizado como atributo teórico do que chamamos de intervenção no espaço urbano, sendo esta uma característica marcante da territorialidade dos grafiteiros.

O que está em questão é identificar o comportamento social do grafiteiro dentro de uma perspectiva geográfica, atribuindo-lhe uma definição mais precisa. A territorialidade será esse elo conceitual no qual se atribui geograficidade ao estudo dos grafiteiros, tomando como referência seu comportamento, em grupo e individual, além de sua relação com o espaço urbano, a cidade e a sociedade de maneira mais ampla.

O geógrafo francês Joel Bonnemaison (2002) desenvolveu em seu estudo sobre o arquipélago de Vanuatu a possibilidade de interpretação sobre a territorialidade em sociedades tradicionais:

Apesar de tudo, a territorialidade de um grupo ou de um indivíduo não pode se reduzir ao estudo de seu sistema territorial. A territorialidade é a expressão de um comportamento vivido: ela engloba, ao mesmo tempo, a relação com o território e, a partir dela, a relação com o espaço "estrangeiro". (...) (BONNEMAISON, 2002: 107) 
Apesar da grande diferença geográfica e cultural do estudo desenvolvido por Bonnemaison, a interpretação da territorialidade analisada junto aos povos tradicionais pelo autor será aqui reportada a um contexto geográfico distinto: a cidade do Rio de Janeiro.

Entendemos que a territorialidade dos grafiteiros não pode ser inteiramente compreendida apenas pelo seu sistema territorial, ou seja, em nossa análise, compreender a ação do grafiteiro e de seu grupo somente dentro dos limites municipais da cidade do Rio de Janeiro ou pelos fatos que ocorrem apenas em um bairro ou localidade dessa mesma cidade é uma avaliação muito limitada. O que de fato passa a ser identificado é que a territorialidade do grafiteiro não deve ser concebida de forma restrita, limitada a um território do Estado ou institucional. Mais do que isso, ela incorpora-se ao próprio tecido urbano, em praticamente toda a sua abrangência, como seu território. Podemos dizer que a territorialidade dos grafiteiros extravasa a própria delimitação territorial da cidade do Rio de Janeiro. A territorialidade se torna, conforme aponta Bonnemaison, "a expressão de um comportamento vivido" - no caso dos grafiteiros, um comportamento vivido no espaço urbano.

Assim a definição mais adequada para o que chamamos de territorialidade dos grafiteiros será caracterizada pela seguinte afirmação de Haesbaert:

A territorialidade, no nosso ponto de vista, não é apenas "algo abstrato", num sentido que muitas vezes se reduz ao caráter de abstração analítica, epistemológica. Ela é também uma dimensão imaterial, no sentido ontológico de que, enquanto "imagem" ou símbolo de um território, existe e pode inserirse eficazmente como estratégia política e cultural, mesmo que o território ao qual se refira não esteja concretamente manifestado - como o conhecido exemplo da "Terra prometida" dos judeus, territorialidade que os acompanhou e impulsionou através dos tempos, ainda que não houvesse, concretamente, uma construção territorial correspondente. (HAESBAERT, 2007: 25)

A definição que Haesbaert propõe a respeito da territorialidade será aqui utilizada balizando o que iremos definir como a territorialidade dos grafiteiros na cidade do Rio de Janeiro. Diferentemente das delimitações e o controle sobre territórios que marcavam a territorialidade conflitante das gangues de imigrantes em cidades como Nova York nos anos 70, 
atualmente no Rio de Janeiro o graffiti não delimita fronteiras entre territórios. É preciso compreender esta territorialidade a partir da imprecisão de limites territoriais para os grupos e/ou indivíduos que fazem o graffiti no Rio de Janeiro, distinguindo-se da proposta de Sack (1986), que circunscreve a territorialidade de um grupo a partir do controle de acesso a seu próprio território. $\mathrm{O}$ grafiteiro desenvolve uma relação simbólica com o espaço urbano, mais especificamente com a cidade, mas não prescinde de suas estruturas físicas (muros, pilastras, edificações) para executar suas intervenções. Portanto, sua territorialidade se constitui a partir da apropriação simbólica e material do espaço urbano.

A seguir identificamos quatro maneiras de ação que hoje estão presentes de forma direta entre os grafiteiros cariocas, e que são definidas a partir da relação que se estabelece entre o grafiteiro e a cidade. Classificadas como bombardeios, mutirões, exposições e oficinas de graffiti, estas representam algumas formas de apropriação do espaço urbano pelo grafiteiro, demarcando sua territorialidade. Cabe ressaltar que estas são características identificadas metodologicamente como forma de criar uma unidade para demonstrar, em nossa análise, como se manifesta e organiza a territorialidade dos grafiteiros na cidade do Rio de Janeiro.

Bombardeios: As ações diretas nas ruas são comumente denominadas pelos grafiteiros de bombardeios. Cunhou-se a palavra bombardeio por se caracterizar literalmente como um ataque rápido e imprevisível a determinados pontos da cidade. Os bombardeios são feitos normalmente em vias de trânsito rápido, ruas com grande circulação de pedestres ou áreas públicas de lazer. (ver figura 1) 


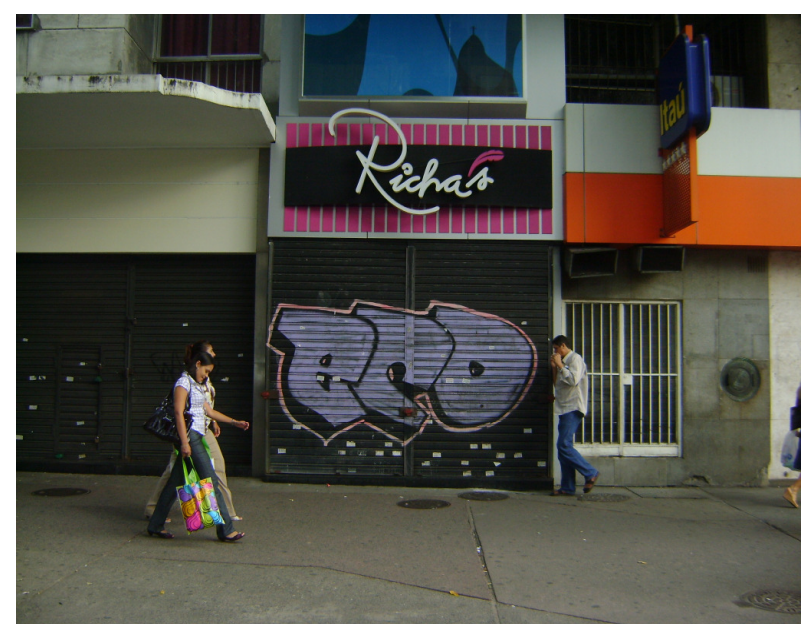

Figura 1. Bombardeio de ECO em um portão de uma loja de roupas - Tijuca. (Foto: Leandro Tartaglia, 2009)

É a proibição que caracteriza o bombardeio de uma superfície. Sendo assim, grande parte dos graffitis que estão expostos na paisagem urbana, em áreas públicas e/ou privadas, são bombardeios. Isto se justifica pelo fato de não terem sido autorizados, seja pelo poder público ou pelos proprietários particulares. É possível dizer que essa é a ação, até certo ponto, mais subversiva dos grafiteiros, a qual denominamos de graffiti selvagem. No entanto, a proliferação dos graffitis pela cidade evidencia que a sua proibição é cada vez menor, o que torna a própria ação de bombardeio mais relativa. Pois se não há proibição, é possível ainda se falar em bombardeio e subversão?

Mutirões: A ideia de ataque à cidade tem sido minimizada, o que de fato tem constituído novas formas de intervenção dos grafiteiros em seus respectivos espaços urbanos. Assim como os bombardeios, os mutirões também constituem a territorialidade dos grafiteiros cariocas, onde as semelhanças terminam. A concepção dos mutirões está ligada à revitalização paisagística de espaços populares, quase sempre considerados degradados, abandonados ou pouco valorizados. Diferentemente do bombardeio, que tem a característica de marcar a paisagem dos bairros e localidades da cidade formal como "cicatrizes" em suas formas urbanísticas, as pinturas realizadas através dos mutirões produzem outras concepções estéticas, especialmente nas favelas. Nessas ações, que 
chamamos de graffitis comunitários, os grafiteiros produzem sua arte buscando uma interação direta com a população local, na qual é desenvolvida a proposta de utilizar o graffiti como elemento de dinamização da cultura. (ver figura 2)

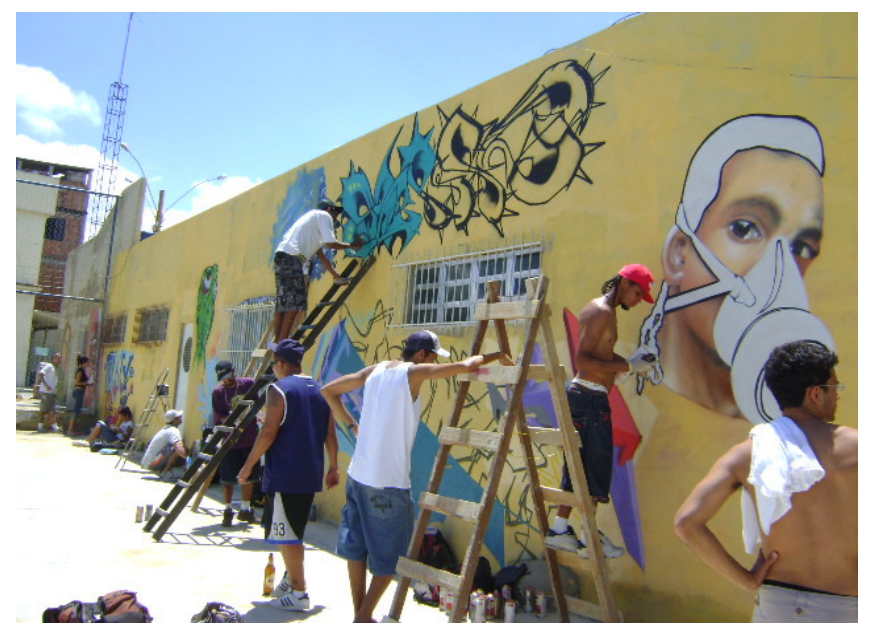

Figura 2. Mutirão de grafiteiros Meeting of Favela - Vila Operária Duque de Caxias RJ. (Fonte: Leandro Tartaglia, 2008)

Exposições: As exposições de graffitis, cada vez mais presentes em galerias de arte e centros culturais na cidade do Rio de Janeiro, apontam para uma dimensão relevante da territorialidade do grafiteiro na cidade. Considerado uma arte pública e efêmera, o graffiti passa por uma sensível transformação destes conceitos quando seus autores começam a participar de eventos dessa natureza.

O graffiti alcançou na atualidade um nível de reconhecimento notabilizado pelo número de intervenções que passaram a ilustrar cada vez mais as galerias de arte, centros culturais, sendo utilizados também na cenografia e na publicidade, imprimindo uma lógica de mercantilização dessa forma artística. O mercado publicitário e os críticos de arte começaram a valorizar o graffiti, e esse foi um fator decisivo que permitiu que um número cada vez maior de grafiteiros brasileiros passasse a ver essa atividade como sua fonte de renda e profissionalização. Essa absorção do graffiti por segmentos da sociedade que outrora a discriminavam permite aos grafiteiros, de um modo geral, criar meios de sobrevivência 
(geração de trabalho e renda) impensáveis há poucas décadas. Isto fica mais evidente em grandes eventos e exposições exclusivas de grafiteiros com apoio e patrocínio de empresas públicas e privadas, além de governos, que atuam desde a divulgação até a realização dos eventos ${ }^{16}$. (ver figura 3 )

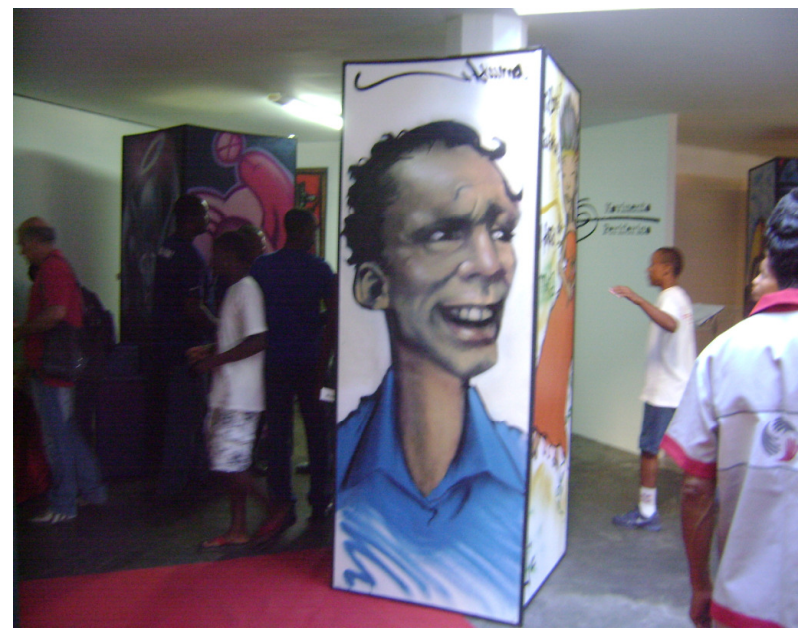

Figura 3. Graffitis na exposição "Movimento Periférico" - SESC Tijuca (Fonte: Leandro Tartaglia, 2009)

A conquista das galerias de arte e centros culturais pelo graffiti no Brasil era algo impensável até os anos 1970, e que a partir dos anos 80 passou a se impor de forma mais veemente no cenário cultural, com artistas paulistanos como Alex Valauri e o grupo "Tupi não dá" no Brasil a exemplo de Michel Basquiat e Keith Harring na Europa e nos Estados Unidos.

$\mathrm{O}$ encerramento das produções de graffitis em espaços fechados e vigiados e a crescente comercialização das obras denotam uma diminuição do caráter subversivo do graffiti e, conseqüentemente, da ação dos seus autores, impondo uma nova lógica a que denominamos de graffiti domesticado.

16 Como exemplo podemos citar a Bienal Internacional de Graffiti de Belo Horizonte realizada no ano de 2008. V. <www.bigbh.com.br/bigbh/htms/index.html > (acessado em 06/10/2008). 
Oficinas: As oficinas de graffiti complementam, de forma significativa, juntamente com as demais características apontadas anteriormente, os aspectos que compõem a territorialidade dos grafiteiros cariocas. As oficinas, uma estratégia territorial pedagógica do hip-hop de transmissão do conhecimento técnico, estético e político dos graffitis (OLIVEIRA, 2006), vêm ganhando cada vez mais espaço (literalmente) na cidade, sendo responsáveis por ensinar e difundir as técnicas do graffiti (uso, tonalidade e combinação de cores, letras estilizadas, entre outras) endossadas por valores da cultura hip-hop. As aulas e a organização dessas oficinas geralmente são feitas por grafiteiros em parceria com projetos sociais e/ou ONGs, utilizando o espaço de centros culturais e sedes de instituições públicas ou privadas. As oficinas funcionam principalmente como "escolas" para grafiteiros iniciantes, o que passa a notabilizar uma frequência considerável de jovens (em sua maioria adolescentes, e até crianças) interessados em desenvolver as técnicas e o conhecimento sobre os graffitis. (ver figura 4)

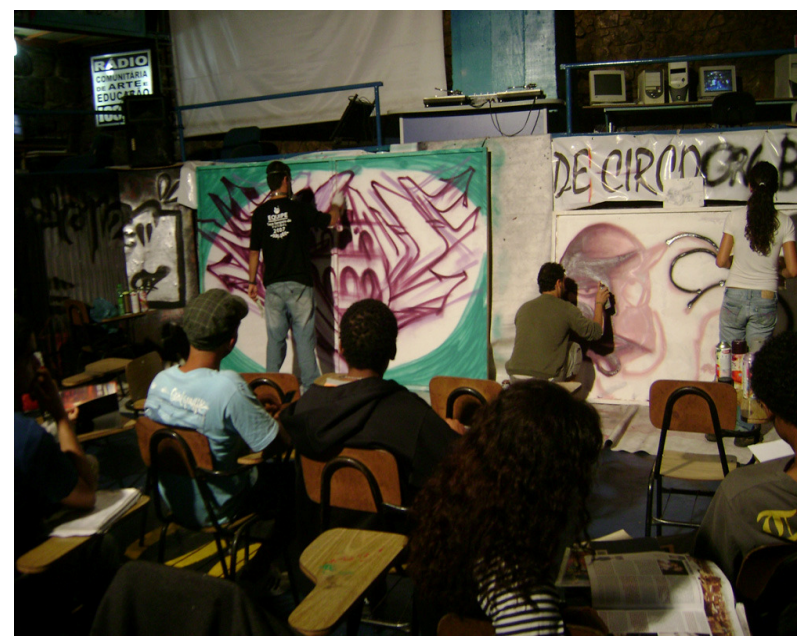

Figura 4. Oficinas de graffiti no CIC - Fundição Progresso - Lapa. (Fonte: CIC, 2008)

A oficina é o espaço que permite o encontro, isto é, um contato mais direto entre grafiteiros, onde são ministradas aulas teóricas e práticas visando desenvolver técnicas artísticas de desenho e graffiti. Nas oficinas, os instrutores são geralmente grafiteiros com uma experiência razoável devido ao seu tempo de atuação. Além de orientar os participantes sobre o processo técnico, esses grafiteiros instrutores também influenciam as 
atitudes de seus "alunos" através do seu próprio comportamento, modo de falar e, principalmente, pelo tempo e forma de atuação. Atribuímos às oficinas a denominação de graffiti pedagógico.

Essas estratégias territoriais têm duração (o tempo que o graffiti persiste na paisagem) e extensão (o alcance social e na paisagem que a obra denota) (SANTOS, 2002[1996]) distintas de outros grafismos, como as pichações. As diferenças na duração e na extensão estão relacionadas às articulações sociais (sistema de parcerias) que os grafiteiros constroem. Já as articulações se dão, geralmente, com ONGs, empresas privadas, movimentos sociais e partidos políticos, que muitas vezes subsidiam a dimensão econômica, criando, em certas ocasiões, tensões na apropriação das intenções dos grafiteiros e da autonomia desses grupos. Ou seja, essas territorialidades revelam uma "autonomia possível" (GUATTARI, 1987) e se envolvem em arenas políticas distintas.

\section{O graffiti e a paisagem}

O que parece evidente, a partir da nossa experiência pessoal, é que a paisagem é uma categoria vital para a identificação do graffiti no espaço urbano. Observar a paisagem é o primeiro recurso, e certamente o primeiro contato, na busca pelos grafismos em questão, seja na perspectiva da Geografia ou de qualquer outra ciência que tenha o graffiti como objeto de estudo.

Augustin Berque ressalta a importância de revelar não só as formas e os aspectos materiais da paisagem, mas também o sentido simbólico que estas adquirem e principalmente como estes são compreendidos e interpretados pela sociedade que a produziu, denotando um constante movimento de transformação do significado dessas paisagens. A paisagem não tem um aspecto imutável - muito pelo contrário, ela está em contínua transformação, sendo modificada nas suas formas, mas, principalmente, resignificada em diferentes momentos.

Do ponto de vista da geografia cultural, que procura, ao contrário, definir essa relação (paisagem/sujeito) não é suficiente (embora seja necessário) explicar o que produziu a paisagem enquanto objeto. É preciso compreender a paisagem de dois modos: por um lado ela é vista por um olhar, apreendida por uma consciência, valorizada por uma 
experiência, julgada (e eventualmente reproduzida) por uma estética e uma moral, gerada por uma política etc. e, por outro lado, ela é matriz, ou seja, determina em contrapartida, esse olhar, essa consciência, essa experiência, essa estética e essa moral, essa política etc. (...) Em resumo: 1) a paisagem é plurimodal (passiva-ativa-potencial etc.) como é plurimodal o sujeito para o qual a paisagem existe; e 2) a paisagem e o sujeito são co-integrados em um conjunto unitário, que se autoproduz e se auto-reproduz (e, portanto, se transforma, porque há sempre interferência com o exterior) pelo jogo, jamais de soma zero, desses diversos modos. O jogo seria de soma zero se a paisagem não tivesse nenhum sentido (isto é, nem significado, nem tendência evolutiva), o que nunca é o caso. (BERQUE, 2004:86, grifo nosso)

$\mathrm{O}$ sentido de paisagem desenvolvido pelo autor, que é simultaneamente uma marca e uma matriz na sua relação mutável com o sujeito, auxilia-nos a compreender o graffiti, que passa a desenvolver esse mesmo jogo de relações no espaço urbano. O graffiti representa a ação de intervir artisticamente por grupos ou indivíduos no espaço urbano, cujas marcas estão repletas de significados decorrentes de sua experiência urbana capaz de exercer influência (ou ao menos disposto a isso) sobre o cotidiano de muitos outros transeuntes da cidade.

Sobre esta concepção de paisagem podemos acrescentar também a perspectiva de Nogué, quando afirma que:

En efecto, el paisaje puede interpretarse como un producto social, como el resultado de una transformación colectiva de la naturaleza y como la proyección cultural de una sociedad en un espacio determinado. (...) los paisajes están llenos de lugares que encarnan la experiencia y las aspiraciones de los seres humanos. Estos lugares se transforman en centros de significados y símbolos que expresan pensamientos, ideas y emociones (...) El paisaje, por tanto, no sólo nos muestra cómo es el mundo, sino que es también una construcción, una composición de este mundo, una forma de verlo. (NOGUÉ, 2007:11/12)

Para o autor citado, a paisagem é uma construção social, ou seja, é, portanto, uma representação do mundo vivido, na qual estão presentes, invariavelmente, as contradições e os conflitos que emanam desse 
processo, denotando o que pode ou não ser visto. A ampla visibilidade de um elemento da paisagem representa aspectos e comportamentos sociais que são toleráveis ou mesmo impostos em uma sociedade. Por outro lado, ocultar elementos de uma paisagem representa certamente a omissão de valores que se queiram suprimir, seja por um consenso ou por imposição de setores hegemônicos da sociedade. Ainda assim, alguns desses elementos podem ter a capacidade de romper (mesmo que ilegalmente) esta lógica determinista, o que se aproxima da discussão em torno do graffiti.

O graffiti caracteriza-se pela sua capacidade de ser visto, isto é, pela visibilidade material e simbólica que tenta adquirir na paisagem urbana em meio a tantos outros elementos edificados e luminosos. A visibilidade denota uma série de elementos simbólicos como a experiência, a representação e como recurso de comunicação que constituem as marcas (grafias) de sujeitos na paisagem da cidade, que alguns autores atribuem à ideia de tatuagens na epiderme urbana (BAUDRILLARD, 1976; SILVA, 2001).

Em grandes metrópoles como o Rio de Janeiro, a visibilidade, ou melhor, a possibilidade de obter essa ampla visibilidade desperta o interesse de diferentes setores da sociedade. Por isso, a paisagem surge como um recurso de comunicação vital para fins publicitários, políticos, artísticos, de vândalos, entre outros, todos em busca de uma parcela de visibilidade que essa paisagem possa influenciar. Armando Silva (2001) discute a diferenciação destes elementos que compõem a paisagem urbana afirmando que:

As imagens da publicidade, porém não são as da arte. Enquanto a publicidade chama a atenção para alguma coisa, a arte o faz para alguém. (...) Já a publicidade, não. Ela mostra, quando mostra (já que também pode indicar ou simplesmente falar), como se o que nos faltasse fosse o que ela nos oferece. Por isso a publicidade "mente", quer fazer-nos crer que podemos ser felizes se conseguirmos o prometido. Seu problema não são os homens em primeiro plano, mas as coisas, mesmo que essas coisas sejam para os homens. Todo o seu imaginário está disposto para o consumo, mesmo que às vezes falhe, e ao tornar-se auto-referência da sua figuração mais do que o produto, ela atua de maneira similar á arte. Mas, por princípio, sua imagem é utilitária. Ela usa todos os 
recursos para fisgar o outro e torná-lo consumidor. (SILVA, 2001:8)

A paisagem urbana é repleta de sinais (informações de trânsito, propagandas, grafismos, edificações etc.), o que faz autores como Armando Silva discutir o significado, muitas vezes antagônico, de alguns desses elementos:

Desse modo, o que se opõe diametralmente ao grafite é a publicidade: enquanto o primeiro busca um efeito social de forte carga ideológica ou, de algum modo, transgressora de uma ordem estabelecida, a publicidade busca o consumo do anunciado e assim sua intenção comunicativa é antes de tudo funcional para um sistema social, político ou econômico. (SILVA, 2001:6)

Há de fato uma disputa por essa paisagem, e isto fica evidente ao observarmos ao longo das avenidas de grande circulação a quantidade de outdoors cobertos por campanhas publicitárias e políticas (principalmente em tempos de eleição). Essas propagandas proliferam por toda a cidade de forma indiscriminada. $\mathrm{O}$ espaço público transforma-se em um espaço publicitário (DUPAS, 2003) e a paisagem pública urbana torna-se assim “(...) um material midiático privado, criando desejos e tratando o cidadão como mero consumidor" (DUPAS, 2003:17). Ë nesse sentido que o graffiti, especialmente na sua vertente mais selvagem (bombardeios), rompe com a lógica da publicidade e do consumo, intervindo como uma manifestação de interesses alheios a estes valores hegemônicos, especialmente porque as intervenções estão mais pautadas pela subjetividade artística no uso da paisagem. A subjetividade e a imprevisibilidade fazem parte de um conjunto de características que podem manter algo do caráter original do graffiti nas cidades, como a subversão e a produção de imagens vibrantes.

\section{Conclusão}

Assistimos hoje a um processo de legitimação do graffiti na sociedade brasileira, que ganha maior notoriedade nas grandes metrópoles como São Paulo, Rio de Janeiro, Belo Horizonte, Porto Alegre, Curitiba, Recife e Salvador. Esta legitimidade é por vezes questionada mediante a dimensão jurídica, que considera o graffiti uma prática ilegal. A 
ambiguidade marca não apenas a condição social na qual a prática do graffiti se encontra; ela marca também determinadas formas de apropriação dos espaços urbanos por grupos juvenis, isto é, sua territorialidade, conforme vimos até aqui. $\mathrm{O}$ aspecto subversivo originário desta prática ainda é possível ser identificado, especialmente pela sua proibição legal. No entanto, esta subversão torna-se cada vez mais branda em decorrência da inserção paulatina dos grafiteiros no mercado formal de consumo ou, como preferem alguns, de sua cooptação. A mídia e os meios de comunicação hegemônicos exercem este papel. Esta crítica é feita especialmente por integrantes do movimento hip-hop, que acreditam no graffiti como ferramenta de transformação e crítica social. $\mathrm{O}$ grafiteiro Airá, O Crespo, explicita melhor este pensamento ao afirmar: "O graffiti é a publicidade do povo". Diante desta afirmação é possível destacar o que Hall aponta:

Já as estratégias culturais capazes de fazer diferença são o que me interessa - aquelas capazes de efetuar diferenças e de deslocar as disposições de poder. Reconheço que os espaços 'conquistados' para a diferença são poucos e dispersos, e cuidadosamente policiados e regulados. Acredito que sejam limitados. Sei que eles são absurdamente subfinanciados, que existe sempre um preço de cooptação a ser pago quando o lado cortante da diferença e da transgressão perde o fio na espetacularização. Eu sei que o que substitui a invisibilidade é uma espécie de visibilidade cuidadosamente regulada e segregada. Mas simplesmente menosprezá-la, chamando-a de 'o mesmo' não adianta. (HALL, 2003: 339)

Concordamos com o autor por acreditarmos que o graffiti expõe uma possibilidade de revisar os valores estéticos hegemônicos que constituem as paisagens urbanas, marcadas pela intolerância e a segregação, ou mesmo diferentes maneiras de se apropriar desse espaço urbano cada vez mais fragmentado. É evidente a crescente espetacularização e cooptação de mercado. No entanto, seu conteúdo crítico ainda persiste, especialmente quando materializado na forma de mutirões e bombardeios. Por ter adquirido uma relativa independência do movimento hip-hop, o graffiti é uma ferramenta que passa a ser utilizada para diferentes fins. Sendo assim, estes outros sujeitos começam a se apropriar distintamente do espaço urbano, constituindo, portanto, novas territorialidades. Abaixo, finalmente, propomos um quadro-síntese sistematizando as principais questões elaboradas ao longo do texto. 


\section{Quadro I}

\begin{tabular}{|c|c|c|c|c|c|c|c|}
\hline $\begin{array}{c}\text { Elemento } \\
\text { s } \\
\\
\text { Grafismo } \\
\text { s }\end{array}$ & $\begin{array}{l}\text { Sentido } \\
\text { observad } \\
\text { o na } \\
\text { paisagem }\end{array}$ & $\begin{array}{l}\text { Difusão } \\
\text { no } \\
\text { Espaço } \\
\text { Urbano }\end{array}$ & $\begin{array}{l}\text { Produção } \\
\text { (objetivos) }\end{array}$ & Autoria & $\begin{array}{l}\text { Conceitos } \\
\text { Envolvidos }\end{array}$ & Recursos & $\begin{array}{c}\text { Tonalida } \\
\text { des }\end{array}$ \\
\hline Pichação & Vertical & $\begin{array}{l}\text { Lógica } \\
\text { da } \\
\text { Repeti- } \\
\text { ção }\end{array}$ & $\begin{array}{c}\text { Simbólica } \\
\text { (vandalis- } \\
\text { mo) }\end{array}$ & $\begin{array}{c}\text { Pichador } \\
\text { es, } \\
\text { Gangues }\end{array}$ & $\begin{array}{c}\text { Território e } \\
\text { Territorialid } \\
\text { ade }\end{array}$ & $\begin{array}{l}\text { Lata de } \\
\text { Jato } \\
\text { (Tinta } \\
\text { spray) }\end{array}$ & $\begin{array}{l}\text { Mono- } \\
\text { cromático }\end{array}$ \\
\hline : & & & i & 4 & $\mathbf{A}$ & & \\
\hline $\begin{array}{c}\text { ' } \\
\text { Grafittis }\end{array}$ & Horizontal & $\begin{array}{l}\text { Lógica } \\
\text { da } \\
\text { Produ- } \\
\text { ção de } \\
\text { Ima - } \\
\text { gens } \\
\text { Vibran- } \\
\text { tes }\end{array}$ & \begin{tabular}{c}
\multicolumn{1}{c}{} \\
Simbólica \\
(Artística)
\end{tabular} & $\begin{array}{l}\text { Movimen } \\
\text { to Hip- } \\
\text { Hop, } \\
\text { Grafitei- } \\
\text { ros } \\
\\
\text { i }\end{array}$ & $\begin{array}{l}\text { Paisagem e } \\
\text { Territorialid } \\
\text { ade }\end{array}$ & $\begin{array}{l}\text { Lata de } \\
\text { Jato (tinta } \\
\text { spray) } \\
\text { pincel, } \\
\text { rolo de } \\
\text { tinta látex }\end{array}$ & $\begin{array}{c}\text { Poli- } \\
\text { cromático }\end{array}$ \\
\hline \begin{tabular}{l}
\multicolumn{1}{|}{} \\
Slogans \\
Políticos e \\
Propagan- \\
dísticos
\end{tabular} & $\begin{array}{l}\text { Horizontal } \\
\text { e Vertical }\end{array}$ & $\begin{array}{l}\text { Lógica } \\
\text { da } \\
\text { Repeti- } \\
\text { ção e } \\
\text { do } \\
\text { consu- } \\
\text { mo }\end{array}$ & $\begin{array}{c}c \\
\text { Funcional } \\
\text { (Consumo) }\end{array}$ & $\begin{array}{c}\text { Empresas } \\
\text {, } \\
\text { Políticos, } \\
\text { Comercia } \\
\text { ntes }\end{array}$ & $\begin{array}{c}\text { Espaço } \\
\text { publicitário }\end{array}$ & $\begin{array}{c}\text { Cartazes, } \\
\text { outdoors, } \\
\text { Lata de } \\
\text { Jato (tinta } \\
\text { spray), } \\
\text { pincel, } \\
\text { rolo de } \\
\text { tinta }\end{array}$ & $\begin{array}{c}\text { Mono - } \\
\text { cromático } \\
\text { e } \\
\text { Poli - } \\
\text { cromático }\end{array}$ \\
\hline
\end{tabular}




\section{ENSAIO SOBRE UMA GEO-GRAFIA DOS GRAFFITIS}

Resumo: Este artigo tem como objetivo compreender como se comportam os grafiteiros no espaço urbano carioca a partir do uso e apropriação da cidade mediante suas intervenções artísticas e capacidade de articulação, e também compreender quais são os fatores que impulsionam ou limitam esta prática, constituindo assim sua territorialidade.

Palavras-chave: Graffiti, territorialidade, paisagem, espaço urbano.

\section{FOR A GEOGRAPHY OF GRAFFITI}

Abstract: This article aims to understand the behaviour of graffiti writers in the urban space of Rio de Janeiro. This use and appropriation of space happens through their artistic interventions and their capacity to articulate relations inside the city, which includes several processes that stimulate or limit this practics as a territoriality.

Keywords: Graffiti, territoriality, landscape, urban space.

\section{BIBLIOGRAFIA}

ABRAMOVAY, M. et. al. 1999. Gangues, Galeras, Chegados e Rappers. Rio de Janeiro: Garamond.

ARCE, J. M. V. 1999. Vida de barro duro: cultura popular juvenil e grafite. Rio de Janeiro: Ed. UFRJ.

BERQUE, A. 2004. Paisagem-marca, paisagem-matriz: elementos da problemática para uma geografia cultural. In: CORREA, R. L., ROSENDAHL, Z. (org.). Paisagem, tempo e cultura. Rio de Janeiro: Eduerj.

BAUDRILLARD, J. 1976. Kool Killer, A Insurreição pelos Signos. L'échange symbolique

et la mort. Paris: Éditions Gallimard.

BONNEMAISON, J. 2002. Viagem em torno do território In: CORREAA, R. L., ROSENDAHL, Z. (org.). Geografia Cultural: Um século (3). Rio de Janeiro: Eduerj.

CHAUÍ, M. 2002. Convite à Filosofia. São Paulo: Ática. 
COSTA, S. R. S. 2002. Bricoleur de rua - Um estudo antropológico da cultura hip hop carioca. Rio de Janeiro: UFRJ/MN/PPGAS (Dissertação de Mestrado).

DE DIEGO, J. 2000. Graffiti. La Palabra y la Imagen: Un estudio de la expresión en las culturas urbanas en el fin del siglo XX. Barcelona: Los Libros de la Frontera.

DOWNING, J. 2002. Mídia Radical: Rebeldia nas Comunicações e Movimentos Sociais. São Paulo: Editora Senac.

DUPAS, G. 2003. Tensões Contemporâneas entre o Público e o Privado. S. Paulo: Paz e Terra.

FOUCAULT, M. 1979. Microfísica do Poder. Rio de Janeiro: Graal.

GITAHY, C. 1999. O que é Graffiti? São Paulo: Editora Brasiliense.

GOMES, P. C. C. 2002. A condição urbana: ensaios de geopolítica da cidade. Rio de Janeiro: Bertrand Brasil, 2002.

GOHN, M. G. 1977. Teoria dos Movimentos Sociais. Paradigmas clássicos e contemporâneos. São Paulo: Edições Loyola.

GUATTARI, F. 1987. Revolução Molecular: pulsações políticas do desejo. São Paulo: Brasiliense.

HAESBAERT, R. 2004. O Mito da Desterritotialização. Rio de Janeiro: Betrand Brasil.

2007. Território e Multiterritorialidade: um debate. In: Revista Geographia, Rio de Janeiro, Ano IX, nº 17, Junho.

HALL, S. 1997. Identidade Cultural na pós-modernidade. Rio de Janeiro: DP\&A.

. 2003. Da diáspora: identidades e mediações culturais. Belo Horizonte: UFMG.

KNAUSS, P. 2001. Grafite Urbano Contemporâneo. In: TORRES, S. (org.) Raízes e Rumos: Perspectivas interdisciplinares em estudos americanos. Rio de Janeiro: 7 Letras.

LEFEBVRE, H. 2006. O direito a cidade. São Paulo: Centauro.

1986. La producion de l'espace. Paris: Anthopos.

LEI DE CRIMES AMBIENTAIS Nº.605, 12 de fevereiro de 1998.

MUNHOZ, D. R. M. 2003. Graffiti: Uma Etnografia dos atores da escrita urbana de Curitiba. Curitiba: Dissertação apresentada ao Programa de Pós-Graduação em Antropologia Social, da Universidade Federal do Paraná. 
NOGUÉ, J. 2007. La construcción social del paisaje. Madrid: Biblioteca Nueva.

OLIVEIRA, D. A. 2004. Por uma significação do movimento Hip Hop. Trabalho de Conclusão de Curso (Graduação em Geografia) Niterói: Universidade Federal Fluminense.

. 2006. Territorialidades no mundo globalizado: outras leituras de cidade a partir da cultura Hip Hop na metrópole carioca. Dissertação de Mestrado apresentada ao Curso de Pós-Graduação em Geografia. Niterói: Universidade Federal Fluminense.

ORTIZ, R. 2003. Mundialização e Cultura. São Paulo: Brasiliense.

PORTO-GONÇALVES, C. W. 2001. Geo-grafias. Movimientos Sociales, Nuevas Territorialidades y sustentabilidad. México: Siglo Veintiuno.

2002. Da Geografia às Geo-Grafias - Um mundo em busca de novas territorialidades. SADER, E. e CECEÑA, A. E. (orgs). La guerra infinita- hegemonía y terror mundial. Buenos Aires: CLACSO.

PENNACHIN, D. L.. 2003. Signos Subversivos: Das significações de graffiti e pichação. Metrópoles contemporâneas como miríades sígnicas; Trabalho apresentado no Núcleo de Semiótica da Comunicação, XXVI Congresso Anual em Ciência da Comunicação, Belo Horizonte/MG, 02 a 06 de setembro.

RODRIGUES, G. B. 2003. Uma Geografia do Hip Hop. Trabalho de Conclusão de Curso (Graduação em Geografia). Niterói: Universidade Federal Fluminense.

SACK, Robert D. 1986. Human Territoriality: Its Theory and History, Cambridge: Cambridge Press.

SANTOS, M. 2008. Metamorfoses do espaço habitado. São Paulo: Edusp, $6^{\mathrm{a}}$ ed.

. 2002 (1996) A natureza do Espaço - tempo e técnica razão e emoção. São Paulo: Editora da Universidade de São Paulo.

SIMMEL, G. 1987. A Metrópole e a Vida Mental. In: VELHO, O. G. $O$ Fenômeno Urbano. Rio de Janeiro: Guanabara.

SILVA, A. 2001. Imaginários urbanos. São Paulo: Ed. Perspectiva.

SOUZA, D. C. A. 2007. Pichação carioca: etnografia e uma proposta de entendimento. Dissertação de mestrado (PPGSA / Programa de pósgraduação em Sociologia e Antropologia). Rio de Janeiro: UFRJ. 
TARTAGLIA, L. R. S. 2010. Geograf(it)ando: a territorialidade dos grafiteiros na cidade do Rio de Janeiro. Dissertação de mestrado (PPGEO-UFF). Niterói: UFF.

WACQUANT, L. 2001. Os condenados da cidade: estudos sobre marginalidade avançada. Rio de Janeiro: FASE. 